\title{
Understanding Innovation Deployment and Evaluation in Healthcare: The Triality Framework
}

\author{
Urvashi Sharma, Julie Barnett and Malcolm Clarke \\ Brunel University, Department of Information Systems and Computing \\ United Kingdom
}

\section{Introduction}

This chapter encompasses two objectives. The first objective is to understand different conceptualisation of technology, context and the user according to various theoretical perspectives within information systems (IS) literature and in the field of healthcare/medical informatics; and in addition, outline perspectives that have expounded the nature of relationship between these three entities. The need to explore such notions stems from authors' interest to elicit how these theoretical perspectives and concepts have been applied in the field of healthcare to understand technological innovation deployment and evaluation processes by taking the tacit, ephemeral, and complicated nature of healthcare work practices into account.

The second objective involves drawing parallels between these two bodies of literature and conceptualising a framework that can be employed to explain how and why technological innovation deployment and evaluation processes in the field of healthcare cause many challenges to arise.

\subsection{Chapter outline}

The chapter starts by drawing on well known theories in the field of IS to study deployment processes. These include the social construction of technology (SCOT), actor network theory (ANT), diffusion of innovation, contextual approach and the work of sociologist, Anthony Giddens in structuration theory and high modernity, and its derivatives in the field of IS by authors such as Barley and Orlikowski. By drawing on these perspectives, the conceptual framework is presented in its skeletal form outlining the salience of considering technological innovation, context, and user as three entities interrelated to each other through recursive relationship.

In the following section of this chapter, theories which provide understanding on deployment and evaluation processes in the field of healthcare are presented. These include theories such as normalisation process theory (NPT), routinisation theory, the structure, process and outcome framework and, concepts such as virtual and invisible work. These theories and concepts provide an insight into the micro-dynamics that occur between the 
context, technology and the user, which in this research, are considered to be the attributes of recursive relationships between the three entities. This leads to the final iteration of the framework, called the Triality framework, according to which, the technology is conceptualised as technological innovation, the context is conceptualised as healthcare social system and the user is conceptualised as human agent. It further highlights that each recursive relationship has set of attributes associated with it and there are nine attributes in total.

By drawing on this framework, this chapter aims at eliciting the complexities associated with healthcare context and the dilemmas surrounding healthcare professionals when technological innovations such as telehealth and electronic records are deployed and evaluated.

\section{Theoretical perspectives from the field of IS: Understanding conceptualisation of technological content, context and user, and the nature of interrelationship between them}

Exploring theoretical perspectives from IS provides insight into how technological content, context and the user have been conceptualised, and what is the nature of relationship between the three entities. Thus, theoretical perspectives that are of essence are discussed next.

\subsection{Social Construction of Technology (SCOT)}

SCOT stems from science and technology studies, which concern themselves with the impact of technology on society and its dynamics. These studies argue that the technology design and its acceptance trajectory are affected by social dynamics within a given society (William \& Edge, 1996). SCOT therefore, strives to explain why certain technological artefacts or "variants" rise in society at given point in time whereas the others "die" (Pinch \& Bijker, 1984). This view was proposed in response to technology determinism that establishes an opposite perspective that technology impacts the surroundings and its users (William \& Edge, 1996). SCOT presents specific conceptualisation of technology, context and the user. These are discussed below.

Technology according to SCOT is conceptualised as an artefact of which the design and use is the subject of various interpretations resulting due to enabling and constraining properties of the technology as experienced by the groups under a given social context (Avgerou, 2002; Bijker, 1995; Klein \& Klienman, 2002; Pinch \& Bijker, 1984; Jackson et al., 2002). This constitutes the concept of interpretive flexibility, which also ascertains that despite different interpretations of an artefact within a society, these interpretations can coexist together as they are dependent on desired outcomes.

In addition, the degree to which a technological artefact is accepted within a society is defined by the concept of closure and stabilisation. Closure is achieved when "all groups' problems have been addressed and groups achieve consensus on a particular design" (Klein \& Klienman, 2002). Stabilization on the other hand, occurs when an artefact no longer requires high specifications. Closure can be attained in two ways, through rhetorical closure where the relevant social group sees the technology as solving the problem that it was intended to 
address, and closure by redefinition of a problem that sees the use of technology as the solution to an entirely different problem than originally proposed. For example, when the prelimatic tyre was originally introduced to solve the vibration problems in cycles, it was rejected; however, when used instead in racing cycles, it was accepted. This illustrates the closure by redefinition of the problem.

Context according to SCOT includes the social and political dimensions. It is argued to shape the values and norms of the groups. It does not however provide detailed insight into this area and has been criticised for this weakness.

The user in SCOT, is conceptualised as a member belonging to a particular social group, who despite sharing a common interpretation of technological artefact as a member of the group also has an individual interpretation which can be subjected to the group's scrutiny over time. This notion is constituted within the concept of technology frames, and has been regarded as its contribution. Another contribution of SCOT includes its attention to the influence of the designer on design during the design process.

However, despite the vital contributions, SCOT has been argued to have drawbacks that include the lack of acknowledging that the design of an artefact might be embedded with a particular group and their intention, and therefore may be unsuitable for other contexts and groups. In addition it is further argued that SCOT does not consider user opinion and extrapolates findings by only following trends (Faulkner, 2009).

In the field of IS, SCOT is furthered by Orlikowski and Gash (1994), who introduced the concept of technology frames of reference (TFR) by drawing on Bijker's notion of the technology frame. According to TFR, the perceptions, expectations and experiences of an individual pertaining to a provided technology, constitute their view and attitude about its nature, value and use. Individuals are argued to have separate and different TFRs and these are often created when a change is introduced that causes disturbance to established routines and work practices (Ciborra \& Lanzara, 1994).

In the case where the TFRs of individuals match, they are called to be in congruence such that "alignment of frames on key elements or categories" exists, but when there are differences, they lead to "incongruence of technology frames" (Orlikowski \& Gash, 1994). Significant incongruence would result in technology being abandoned, while congruent technology frames would achieve use and become embedded in routines.

By drawing from SCOT and TFR, it can be argued that users of technology constitute perceptions as frames that are influenced by their interaction with their surrounding environment and group members (Davidson, 2006; Davidson, 2002; Davidson, 1997). These frames govern their reaction to any change introduced and if congruent then positive impacts such as use of provided technology can be achieved. On the other hand, if incongruent frames dominate, the use of technology will cease and efforts to deploy or evaluate would be wasted. The notion of frames discussed here and the way in which SCOT views the three entities of context, technology and the user, facilitates to draw holistic definition of each of the three entities in Triality Framework. The framework is presented later in the chapter.

The focus now moves to ANT which differs greatly from SCOT in terms of its analytical approach. 


\subsection{Actor Network Theory (ANT)}

In actor network theory (ANT), there is no analytical difference between a technology artefact and a human user (Latour, 1999; Greenhalgh \& Stones, 2010). Both are described as actants that pose as an agency, and together aim at achieving a goal within a heterogeneous network, while drawing on artefacts, text, conventions such as money, people or a hybrid of these intermediaries.

An agency that is described as the technical artefact and human user is argued to be semiotically equivalent; which requires thinking symmetrically about human and nonhuman agents. Both Pickering $(1993)$ and Orlikoswki $(2007,2008)$ favour the use of this notion and have extended it. For example Pickering introduced the notion of the 'Mangle of practice', according to which, he argues that the human agency and the machine agency are temporally emergent in practice, with the goals of the human agency governing the outcome. In other words, human agency uses technology as its "temporal extension" and by which it can succeed in its endeavours. He further suggests that it is the interaction between the human agency and the machine agency which leads to resistance and accommodation.

More recently, using the underlying philosophy of ANT, Orlikowski (2007) introduced the concept of 'Cognitive entanglement', which "presumes that there are no independently existing entities with inherent characteristics". The entities in this statement pertain to the context, technology and the user. The notion suggests that there is no recursive relationship between the entities, and according to this approach the "focus is on agencies that have so thoroughly saturated each other that previously taken for granted boundaries are dissolved" (Orlikowski, 2008).

An approach encompassing such a perspective towards technology and human as a user is favoured because its argued to solves the problem of representation (Pickering, 1993; Orlikowski, 2007, 2008); which because of the subject object dichotomy employed within other perspectives, fails to acknowledge the issues arising due to power imbalance and shift in knowledge that occurs when a technological artefact is introduced within heterogeneous networks (Latour, 1999).

A heterogeneous network in ANT is a reference to the context in which human-machine interactions are situated (Law \& Callon, 1992). The context is governed by sociology of translation. Translation here refers to the processes and actions that are involved in achieving a result due to the interaction between the actants, and it depends upon irreversibility and alignment of the interests of the actors with the overall network aims and goals. In addition, it is suggested that networks are successfully translated when they conform to the regulation, norms (local) and are constituted by legitimate actors. Such translations allow networks to converge and therefore, be effective and durable (Avgerou, 2001, 2002). This notion of sociology of translation is applied in the field of healthcare by Nicolini (2010) in his work to understand the adoption and assimilation of telemedicine innovation.

Among the main drawbacks of ANT is its analytical dimension in which human and machine agencies are treated as the same (Pickering, 1993; Avgerou, 2002). Labelled as the post-humanist approach, it is argued that the use of this analytical lens crumbles when the complexity and number of networks increases. In addition, it is debated that the context in which both human and nonhuman actors interact is only acknowledged to be politically influenced and the social and cultural avenues are ignored. 
However, the very criticism of ANT is also seen as its main strength as some argue that by using such an analytical concept, ANT accounts for negotiating, redefining and appropriation of interest of human actors and those "inscribed within a technical artefact" (Orlikowski et al., 1996). One example that used the notion of negotiation in healthcare is study where the implementation of telehealth is studied, and it is argued that the interaction resulting between context, information communication technology (ICT), and the user due to ICT implementation is a social process. It requires negotiating between power, politics and meaning encompassed within ICT and its intended use (this concept uses the term ICT instead of IS innovation) (Constantinides \& Barrett, 2006a, 2006b).

Another important concept that ANT provides is that of normalisation. This concept facilitates understanding about technology and its assimilation within networks. More importantly this concept highlights the longitudinal nature of technology assimilation by users in their routines (Avgerou, 2002).

In addition, ANT's concept of 'Unintended consequences' outlines that the outcomes of introducing technology in a network might not always be desired and expected, and that unintended ways of technology use increases when users and designers are spatially absent or distanced (Nicolini, 2007). One study using this concept in healthcare (Harrison et al., 2007) suggested that unintended consequences can be attributed to the change introduced by the healthcare information technology (HIT) implementation, and that the role of such unintended consequence can be assessed by evaluating five types of sociotechnical interactions, shown in the form of an interactive sociotechnical analysis (ISTA) model. The model allows examination of the actual use of HIT, the impact of the technical and physical settings of work on HIT, users' interpretation of HIT use, and the recursive dependence of these factors on each other.

The enhanced understanding that ANT provides on conceptualisation of technology, context and the user is drawn upon while defining these three entities within Triality Framework.

So far, we looked at the variants of Science and Technology Studies (STS), the focus now moves to another theoretical perspective, Diffusion Of Innovation (DOI). This perspective provides a valuable understanding on how technology diffuses within a society by perceiving technology, context and the user from different perspective.

\subsection{Diffusion of innovation}

In this perspective, technology is conceptualised as innovation where innovation is encompassed in a broad definition as "an idea, practice, or object that is perceived as new by an individual or other unit of adoption" (Rogers, 2003). An innovation is argued to have five attributes of: relative advantage, compatibility, complexity, trialability, and observability. The definition of each attribute is presented in table1.

Innovation as technology is also suggested to be a composite of hardware and software, and an enabler of accomplishing actions to achieve desired goals.

The context according to this perspective is a social system consisting of social structures and norms. The structures are a type of information that regulate the individual's behaviour and are defined as "patterned arrangements of units in a system". Norms on the other hand are 
defined as regularised behaviour patterns that are acceptable. The notion of a social system is inclusive of an organisation or a network of organisations. When an innovation is proposed, an organisation is argued to go through a process of innovation which, involves defining organisational need, matching the need with an innovation, going through the process of redefining and restructuring the innovation and organisational routines to achieve fit, clarify if any gaps remain, and finally achieve routinization where innovation is accepted with activities such that it "loses its identity" over time (Rogers, 2003; Lee 2004).

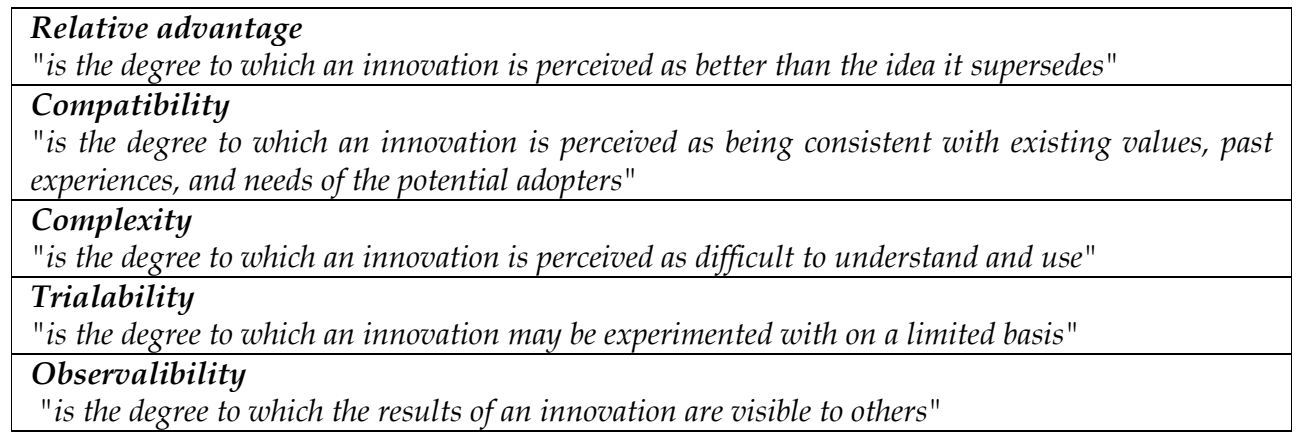

Table 1. Five attributes of innovation (taken from Rogers, 2003)

The user, according to this perspective is understood to be an individual who is a part of the innovation-decision process that involves mapping the journey of an individual through gathering knowledge on the innovation, developing a perception towards the innovation, evaluating and taking the decision to either accept or reject the innovation, use the innovation, and finally confirm the decision (to use it or not). The user is also conceptualised to communicate his/her understanding about the technological innovation to the other individuals within the social system, thus, impacting its diffusion.

One of the main contributions of this perspective is the concept of consonance and dissonance, which argues that an individual's behaviour is attributed to their constant effort towards eliminating or reducing the uncomforting feeling due to change. In IS, this notion is used to understand how use of IT changes work practices at a micro level, and how practices change due to perceived dissonance between the context, technology and the action entailed within practices. Overtime, individuals enact practice as routines to experience consonance (Vaast \& Walsham, 2005).

This perspective also proposes that the change in social structures and norms due to the introduction of innovation leads to resistance (Greenhalgh et al., 2008). Using this perspective to understand the diffusion of electronic records in the NHS. U.K. resulted in a conceptual model that considers "the determinants of diffusion, dissemination, and implementation of innovations in health service delivery and organization" (Greenhalgh et al., 2004; Greenhalgh et al., 2008).

This perspective and how it had been used by other authors to understand the processes that impact diffusion of innovation provides a valuable contribution to the framework in this work to conceptualise the context, technology and user. 
Having discussed theories that acknowledge the three entities of technology, context and the user as important yet do not discuss the nature of relationship between these three entities, we move our attention to the theories that provide such conceptualisation of relationship between the entities. These theories and concepts include the contextualist approach, the structuration theory and the technology-in-practice. We start with contextualist approach that elaborates on the recursive relationship between the (technological) content and the context.

\subsection{Contextualist approach}

The contextualist approach elucidates the importance of considering context when studying change and the processual nature of such a change. According to this approach, context is conceptualised to consist of outer and inner contexts. The outer context refers to interorganisational conditions such as political, social, economical and competitive environment (Pettigrew, 1985, 1987, 1997). On the other hand, inner context accounts for intraorganisational aspects such as structure, organisational culture and political circumstances.

In IS, the contribution of the contextualist approach is considered important as defining the context can be often problematic (Avgerou \& Madon, 2004); and by extrapolating this notion to IS, context can be defined as a set of variables that affect information systems and in turn are influenced by it. This is termed "the environment", and informs that context should be considered as emergent (Avgerou, 2001).

Conceptualisation of technology according to this perspective is that of a content that can be understood as "the particular areas of transformation under investigation" (Pettigrew, 1987). Apart from introducing new technology, when viewed from the perspective of organisational context, these areas of transformation can also include geographical positioning, change in organisational culture and work force. It may be further argued that content and context are bound in a mutual relationship, where one is continually shaped by and shapes the other. Outlining the recursive relationship between content and the context is one of the contributions of this approach (Pettigrew, 1985, 1987, 1997).

The relationship between context and content is enabled through process, where process encapsulates the actions, reactions and interactions of the various parties that are involved in changing of an organisation from one state to another (Markus \& Daniel, 1988; Pettigrew , 1987). Thus, it represents continuity and interdependent sequence of actions and events related to a given phenomena and allows understanding of its (phenomena's) origin, continuance and resultant outcome. At an actor level, process is represented and described by verb forms such as interacting, acting, reacting, responding and adapting. Whereas, at a system level, emerging, elaborating, mobilizing, continuing, changing, dissolving and transforming describe process.

The strength of the contextualist approach lies in the provision of "guiding assumptions" to carry out the research appropriately (Pettigrew, 1997). Among these assumptions is the inclusion of vertical and horizontal analysis. It is argued that having multiple levels of analysis enables the emergent and situational nature of process under the given context to be captured. Analysis at the vertical dimension includes studying group dynamics and organisational issues, and the interrelationship between those levels. Horizontal analysis involves interconnecting longitudinally the phenomena of interest studied at the vertical 
level (Pettigrew 1987, 1990, 1997; Pettigrew et al., 2001; Walsham \& Waema, 1994; Walsham 1993). Such form of analysis suggests that a theory or theories can be used as a motor to drive analysis, and that the processes under analysis should be linked to the outcome.

In IS, this approach is adhered to link content, context and process to the "'what', 'why' and 'how' of evaluation", where it is argued that "effective evaluation requires a thorough understanding of the interactions between these three elements" (Symons, 1991). In the field of healthcare, the contextualist approach is used to understand the adoption, use and diffusion of telehealth, and it is argued that the contextualist approach through its characteristic of facilitating multi-level analysis allows the researcher to "study network-level innovations involving multiple organizations and stakeholders" (Cho, 2007).

This perspective offers a valuable contribution to Triality framework as it confirms the recursive relationship between the entities of context and technology.

The focus now moves to structuration theory which introduces the concept of 'Duality of structure', emphasising that there exist a relationship between the context and the user.

\subsection{Structuration theory}

According to structuration theory (ST), the changes in social systems are not simply an outcome of either human action (subject to knowledgeability) or social structures, but a product of their interaction. This relationship of simultaneous mutual shaping is known as the 'Duality of structure', which is "that the structural properties of social systems are both the medium and the outcome of practices that constitute those systems" (Giddens, 1979). In other words, there exists a recursive relationship between the user (in this theory called human agent) and the context (in this theory termed social system), and thus, it offers a valuable contribution to Triality framework as it confirms the recursive relationship between context and the user. Understanding this reciprocal and recursive relationship involves three main concepts: the social system, structure and the human agency.

Social systems are the reservoir of recursive social practices that human agents enact daily. In modern social system, these practices are institutionalised and constitute deeply embedded routine work; changes to which are resisted. The rules and resources that human agents draw on, and simultaneously enact while accomplishing their daily routine through interaction within the social systems, are known as structures. Structures reside in human "memory traces" and are argued to be solely dependent on human engagement. Structures are further argued to the facilitators and the constrainers of the human agent's engagement (Giddens 1979, 1984).

It is suggested that the structure are produced and reproduced through human interaction and therefore, constitute the 'Duality of structure'. For example, structure of signification (structures of meaning) is enacted by human agents by drawing on their interpretive scheme, through communication, to evaluate the underlying motive of their actions and those around them. The structure of domination is enacted when human agents exercise power through facilities such as ability to locate resources (Walsham, 1997; Walsham \& Han, 1991). The structure of legitimation is enacted when agents assess their actions and sanction them through norms (morality and ethics) (Giddens 1979, 1984, 1990, 1991; Sharma et al., 2011). 
The above notion also implies that human agents have an inherent capacity to act and transform with an exercise of power (transformative capacity), and this is called the 'agency'. Furthermore, 'agency' is argued to be reflexive in nature such that human agents continually monitor their actions and that of others. In essence, it can be argued that in order to enact new routines, the agents utilise reflexivity and transformative capacity to enhance their knowledgeability which in turn reciprocates their decisions (Giddens 1979, 1984, 1990, 1991; Sharma et al., 2011).

The structuration theory has been widely acknowledged in various fields, and especially in IS (Jones et al., 2004; Sharma et al., 2011). However, there are challenges that need to be overcome when using this theory, and these are described next.

The first challenge faced when using structuration theory is that it encompasses number of concepts that are used to elucidate the 'Duality of structure'. This affects the applicability of ST in the field of IS, and presents a dilemma of whether to use the theory in its entirety (as a meta-theory) and risk abandoning salient concepts, or use specific concepts and risk losing its overarching perspective (Walsham \& Han, 1991; Thompson, 2004; Jones \& Karsten, 2008). However, one solution is to use specific concepts to facilitate detailed and meaningful exploration of a problem.

The second potential challenge of applying ST to the area of IS is its lack of focus on technology (DeSanctis \& Poole, 1994; Pozzebon \& Pinsonneault, 2005). This can be mapped onto adopting a nominal view about technology (Orlikowski \& Icano, 2001). Many IS researchers have acknowledged this as a critical gap and have provided ways in which this can be addressed (Barley, 1986; Orlikowski 1992, 2000). These efforts are described next.

\subsubsection{The scripts}

One of the first examples of the use of ST to study the effects of technology introduction was to expound how the computed tomography (CT) scanners introduced in the radiology department of two hospitals enabled enactment of different structures (Barley, 1986). However, in order to overcome the lack of emphasis on technology in structuration theory and its effect on the interaction between agents and thus the structures enacted, the technology was defined as "an intervention into the relationship between human agents and organisational structure, which potentially changes it" (Orlikowski \& Baroudi, 1991).

Moreover, by drawing on the duality of structure, other peripheral concepts within ST were diminished and the concept of 'scripts' was introduced, which was termed as "observable, recurrent activities and patterns of interaction characteristic of a particular setting" (Barley \& Tolbert, 1997). This allows the link between action and institution to be explored using structuration theory and organisational theories, with a resultant sequential model of institutionalisation that has four "transition states" or moments based on scripts: encode, enact, replicate or revise and, externalise and objectify. These being a representative of practices that are enacted and in the light of changes, they are replicated or revised and eventually become part of daily routine or institutionalised.

The institutionalization model may be extended to explore the relationship between deployment of new technology and expertise (Black et al., 2004). This was achieved by applying mathematical modelling to ethnographic data, to determine how differences in the 
expertise of users affect their willingness to collaborate with others. It is suggested that enhancing users' knowledge on using technology does not necessarily guarantee its use and improved outcome. Instead, the success of technology is related to distribution of expertise amongst the users, where, the concept of relational distribution is explained as "a relative balance in operational knowledge" (Black et al., 2004).

\subsubsection{Technology-in-practice}

In 'Duality of technology', the technology is considered as an artefact embedded with structure, where structures are defined as the "mental models" that human agents enact while drawing on the rules and resources available to them and interacting with colleagues and the environment (Giddens 1979, 1984; Orlikowski 1992). An artefact is described as a tool that may be employed for intended use or other purposes, some of which may be completely unrelated to the original (Orlikowski \& Iacono, 2001). Furthermore, it is the user's contextual surroundings that might influence the way in which the tool is used or allow for its use to be re-invented (Orlikowski, 2000; Constantinides \& Barrett, 2006a, 2006b; Pettigrew, 1987).

However, the idea of an artefact embedded with structures contradicts the emergent use of technology and therefore, Orlikowski proposed an enhanced view in 2000 in which she proposed technology-in-practice lens that distinguishes between technology not in use and technology in use. According to this lens, it is argued that technology is to be considered as an artefact when not used but, when agents in their daily routines use technology, it becomes 'technology-in-practice', where structures of technology use are enacted by agents while they use and interact with a given technology in a given context (Orlikowski, 2000).

The phenomenon of emergent technology-in-practice was studied in three different organisations, all using the same technology (the Notes), and identified three types of enactment and six types of technology-in-practice (Orlikowski, 2000; Orlikowski \& Barley, 2001; Orlikowski, 1993). It is observed that the types of enactments (structures enacted) are distinguished by the degree or extent of change in the process, technology or structure (context), which are termed as "interactional, technological and institutional consequence" respectively. Change in technology would result in the first type of enactment, "inertia", which is characterised by limited-use technology-in-practice. Change in technology and process would result in "application" as enactment and could involve collaboration, individual productivity, collective problem solving and process-support as technology-inpractice. The third type of enactment, "change", would involve improvisation technology-inpractice and is usually observed when there is a significant modification of the process, technology and structure.

This perspective offers a valuable contribution to Triality framework, as it confirms the recursive relationship between the technology and the user.

\subsection{Conceptualising technological content, context and the user}

Section one has presented theoretical perspectives to provide an understanding of the conceptualisation of technology, context, the user and the nature of relationship between them (See table2 below). 


\begin{tabular}{|l|l|l|l|}
\hline Theory & $\begin{array}{l}\text { Conception of } \\
\text { context }\end{array}$ & $\begin{array}{l}\text { Conception of } \\
\text { technology }\end{array}$ & $\begin{array}{l}\text { Conception of the } \\
\text { user }\end{array}$ \\
\hline $\begin{array}{l}\text { Social Construction } \\
\text { of Technology }\end{array}$ & $\begin{array}{l}\text { Social context - } \\
\text { society that is } \\
\text { politically and } \\
\text { economically } \\
\text { influenced }\end{array}$ & Artefact (designed) & $\begin{array}{l}\text { Social group } \\
\text { comprising of } \\
\text { individuals }\end{array}$ \\
\hline $\begin{array}{l}\text { Actor Network } \\
\text { Theory }\end{array}$ & $\begin{array}{l}\text { Politically driven- } \\
\text { power play }\end{array}$ & $\begin{array}{l}\text { Actant with semiotic } \\
\text { agency }\end{array}$ & $\begin{array}{l}\text { Actant with semiotic } \\
\text { agency }\end{array}$ \\
\hline $\begin{array}{l}\text { Diffusion of } \\
\text { innovation }\end{array}$ & $\begin{array}{l}\text { Social system } \\
\text { inherent to which are } \\
\text { structures and norms }\end{array}$ & Innovation & $\begin{array}{l}\text { Individual with goals } \\
\text { to achieve and ability } \\
\text { to learn and draw on } \\
\text { experiences }\end{array}$ \\
\hline $\begin{array}{l}\text { Contextualist } \\
\text { approach }\end{array}$ & Inner and outer & Content & $\begin{array}{l}\text { Actor whose } \\
\text { interacting, acting, } \\
\text { reacting, responding } \\
\text { and adapting }\end{array}$ \\
\hline $\begin{array}{l}\text { Structuration } \\
\text { Theory }\end{array}$ & Social System & - & $\begin{array}{l}\text { Human agent with an } \\
\text { agency, and who is } \\
\text { always involved in } \\
\text { reflexivity of actions }\end{array}$ \\
\hline
\end{tabular}

Table 2. Conception of context, technology and user according to different theoretical perspectives

Taking the essence of these perspectives into account, this research conceptualises technological content as IS innovation, context as healthcare social system, and the user as human agent. It further argues that a recursive relationship exists between each entity. This results in a conceptual framework that combines the congruent relationships, and enhances the common. This framework is called the Triality framework.

\subsubsection{Conceptualising technological content as technological innovation}

The term technological innovation is used to represent 'technology' in the Triality Framework as it ensures that technology is understood not just as an artefact, but rather a modality with emergent and dynamic use. Furthermore, although the innovation may be embedded within an overall vision, the way it is to be used is not fixed, and users may alter or modify it. This not only accounts for the attributes of innovation as outlined by Roger (2003) but also provides an explanation of the ways in which human agents in social systems enact practices, and how the process of enactment is facilitated through using innovation as a mediator, where its use can be improvised through the ability of the agents to learn and circumnavigate (Orlikowski, 2000, 2002).

This conceptualisation approach takes into account the ensemble view of technological artefact which focuses on "dynamic interactions between people and technology whether during construction implementation or use in organizations or during the deployment of technology in society at large" (Orlikowski \& Icano, 2001). Moreover, ensemble view is highly apt for a complex context as healthcare (Chiasson \& Davidson, 2004). 
This notion also supports the view that where an innovation is considered to be a part of social change, it may be an enabler and a constrainer of actions due to various institutional, organisational, social, rational and idiosyncratic reasons (Avgerou, 2001; Avgerou \& Madon, 2004).

The technological innovation term further includes the property of 'informate' where information technology possesses the duality whereby through its ability to automate the organisational transactions it also "create(s) a vast overview of an organisation's operations, with many levels of data coordinated and accessible for a variety of analytical efforts" (Zuboff, 1988)

\subsubsection{Conceptualising context as healthcare social system}

The introduction of technology in healthcare system introduce a number of changes to overall healthcare delivery, including the context where care is delivered and the way in which it is delivered (Boddy et al., 2009). This can result in factors contributing to conflict among its users and contradiction in overall goals ( May, 1993; May et al., 2001, May \& Ellis, 2001; May et al., 2003a; May et al., 2004; May et al., 2005; Whitten \& Adams, 2003; Whitten \& Mickus, 2007; Whitten \& Mackert, 2005; Wootton et al., 2006). Studying and understanding such contextual changes can be facilitated by using ST and high modernity (Gammon et al., 2008; Hardcastle et al., 2005; Kouroubali, 2002; Lehoux et al., 2002; Peddle, 2007; Walsham, 1997; Whitten et al., 2007).

However, to apply this approach appropriately, IS innovation based services such as telehealth and electronic records have to be seen as an extension of a healthcare social system that spans across time and space. For this, Giddens's definition of social system and concept of disembedding mechanism will be called upon. As a healthcare system involves institutionalised practices, and by recalling the definition of a social system presented earlier (in SCOT, diffusion of innovation and ST), it is argued that a modern healthcare system can be perceived as a large social system that contains individuals interacting with each other, and whilst doing so, they enact various structures through continuous reflexive monitoring of their actions. Endogenous to these social systems are the disembedding mechanisms, to which, Giddens alludes as "lifting-out" of social relations from local contexts of interaction and their restructuring across indefinite spans of time-space" (Giddens, 1990). The concept of disembedding mechanisms was introduced by Giddens in Consequences of Modernity $(\mathrm{CM})$, whereas opposed to his earlier work, Giddens reflects on the role of technology as a facilitator and contributor to the "stretching" of modern social systems (Giddens, 1990, 1991).

There are two types of disembedding mechanisms, symbolic tokens and expert systems, which collectively are termed as abstract systems (Giddens, 1990). Symbolic tokens such as money are defined as "media of interchange which can be "passed around" without regards to the specific characteristic of individuals or groups that handle them at any particular juncture" (Giddens, 1990). Expert systems on the other hand are described as "systems of technical accomplishment or professional expertise that organise large areas of the material and social environments in which we live today" (Giddens, 1990).

Comparing these definitions, technology can be understood as an expert system that combines "technical accomplishments" of equipment such as telehealth and electronic records with "professional expertise" of clinicians aimed at organised delivery of care for patients in a modern healthcare system. 
It is not clear why the two disembedding mechanisms taken together should be called an abstract system, and therefore this research uses a modified definition where an abstract system is depicted to encompass an expert system organised and structured around care delivery processes. This modified perspective has two inherent advantages. From a theoretical point of view, it acknowledges all the pivotal concepts related to the abstract system without losing its central meaning (no interdependence is ascribed between the expert system and the symbolic token by Giddens, therefore subtracting symbolic tokens from abstract system studied should not affect its functionality). From a practical view, this perspective allows the contextual differences between traditional care delivery practices and technology based practices to be distinguished.

As an expert system, technology based healthcare delivery services create systems where the experts within the system meet lay people (Giddens, 1990). The interactions within such systems are based on trust and expertise.

Within this research, the 'context' may be substituted as the 'social system' which better describes a setting such as healthcare. Furthermore, using the term 'healthcare social system' in place of 'context' in the Triality framework acknowledges that modern organisations are extensions of social systems, and enables various dimensions such as political, economical and social conditions to be incorporated in the definition of context (Pettigrew, 1987; Van de Ven \& Garud, 1993).

This approach also provides understanding of the dynamics of technology deployment and organisational discourse as instigator of social change (Avgerou, 2001) and as an interacting entity (Dopson et al., 2008).

\subsubsection{Conceptualising user as human agent}

The user of technology has been defined within IS deployment research as an actor with habitus, such as in ANT (Schultze \& Boland, 2000; Latour, 1999). In this research, the term 'human agent' is considered more appropriate as it acknowledges that humans have an 'agency' that is their inherent capacity to act. This 'agency' is engaged in reflexivity where each action taken is reflected upon and learned from. By doing so, the human agents enact new routines and employ transformative capacity (power) to enhance their knowledgeability (Giddens, 1984; Edmonson et al., 2007). The term "agency" also enables intentionality and choice to be considered. It may also be argued that despite the constrictive nature of context; agents have freedom of choice as "people are purposive, knowledgeable, adaptive, and inventive agents who engage with technology in a multiplicity of ways to accomplish various and dynamic ends. When the technology does not help them achieve those ends, they abandon it, or work around it, or change it, or think about changing their ends" (Orlikowski, 2000).

Therefore, if this notion of agency is extended to understand technology deployment at the individual level, it can be argued that human agents will adopt and enact practices that influence the way the technology is used within a given context; and due to the recursive nature of this relationship, these adopted and enacted practices will in turn influence their perceptions of the technology. They weave a complex web of interpretation (which is influenced by previous experience, interaction with colleagues and the work environment) around the technology whilst making sense of it, it's real purpose and usefulness; and in doing so they lay the foundations of their interaction with the IS innovation that ultimately 
determines whether they will use it and accept its use as part of their daily routine or circumnavigate and resist its use. This notion also suggests that such a process of sense making can be lengthy, as the structures enacted by human agents are temporal in nature, that is, while some structures change quickly, others might change much more slowly (Barley, 1986; Barley \& Tolbert, 1997; Black et al., 2004).

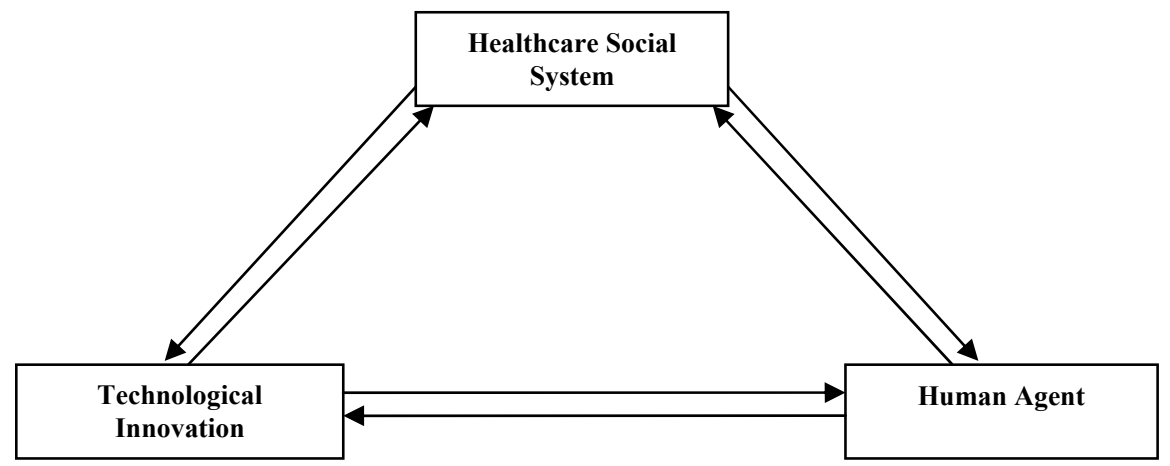

Fig. 1. Triality framework (initial version)

It is noted that when studying the processes within healthcare, in addition to the broader view, understanding dynamics between the three entities is also essential due to the complexities (of healthcare context and processes) involved. Therefore, in the next section, perspectives providing insight into such dynamics are presented. This also enables the perspectives discussed earlier to be aptly summarised and provide a holistic understanding of the deployment and evaluation efforts in the field of healthcare.

\section{Theoretical concepts from healthcare and medical informatics literature: Impact of innovation deployment and evaluation}

The perspectives discussed in this section contribute to Triality framework in number of ways. These perspectives outline the impact of introducing healthcare intervention such as telehealth and electronic records on routines and work practices of healthcare professionals over time, and also acknowledge the impact of such change on the expertise of healthcare professional, interaction during clinical encounter, and quality of care. It can be argued by drawing on these perspectives that such changes might influence healthcare professionals' decision to accept the IS innovation in daily routines.

In addition, these perspectives provide an understanding of complex processes and dynamics within healthcare systems, which can be attributed to the recursive relationship between the context of social system, the content of IS innovation and the human agent as the user. This enables the Triality framework to be updated.

\subsection{Change in work practices and routines: The concept of normalisation, and routinisation}

Routines are enacted because they involve guiding, accounting, referring, creation, maintenance, and modification. Individuals continuously adapt their routines with 
experience and by reflecting on previous outcomes, and routines rather than being stable are subjected to constant change (Feldman, 2000, 2003; Edmonson et al., 2007).

Routines have four attributes that include the repetition, recognisable pattern of action, multiple participants, and interdependent actions. Taking this notion into account, individuals within an organisation can be argued to share understanding of routines and the process of its enactment, and as a result of enacting dependent and interconnected routines lead to organisational routine which encompass ostensive and performative aspect (Feldman \& Rafeali, 2002). The Ostensive aspect "is the ideal or schematic form of a routine. It is the abstract, generalized idea of the routine, or the routine in principle". Performative aspect on the other hand, is described to "consist of specific actions, by specific people, in specific places and times. It is the routine in practice" (Feldman \& Pentland, 2003). As a consequence, whether a change will be accepted and routinised depends upon the "processes of variation, selection and retention that take place between the ostensive and performative aspect" (Feldman \& Pentland, 2003).

Extending the concept that organisational routines are a result of mutual action that is interdependent, a hospital setting can be considered a as negotiated order, or in other words, the healthcare context can be considered as comprising "practice(s) in which various actors are expected to be relevant partners in specific work processes" (Tjora \& Scambler, 2009).

A similar approach is advocated by Greenhalgh and colleagues (Greenhalgh, 2008; Robert et al., 2009, 2010), where they considers that routines in medical settings overlap with each other and are impacted by changes at different levels, such as changes in the wider environmental context, organisational context, and individual context.

It is further argued that implementing an IS innovation or complex healthcare intervention such as telehealth and its evaluation strategy such as RCT, changes routine of professionals, and that it takes time for professionals to accept such changes (May \& Ellis, 2001; May, 2006a, 2006b). This is called normalisation, and can be understood as "the embedding of a technique, technology or organisational change as a routine and taken-for-granted element of clinical practice", and is argued to consist of a set of endogenous and exogenous processes (May \& Finch, 2009; May et al., 2007a, 2007b; Mair et al., 2007a, 2007b). In this context, endogenous processes refer to processes that govern the patient-professional encounter; and exogenous processes refer to organisational structure, culture and division of labour.

The concept of normalisation has now been developed into normalisation process theory (NPT) that provides "a robust and replicable ecological framework for analysing the dynamic collective work and relationships involved in the implementation and social shaping of practice". The main postulate of theory is that the work in enactment of practice is governed by four generative mechanisms of human agency. These are: Coherence which is "work that defines and organizes the objects of a practice", Cognitive participation which is "work that defines and organizes the enrolment of participants in a practice", Collective action which is "work that defines and organizes the enacting of a practice", Reflexive monitoring "work that defines and organizes the knowledge upon which appraisal of a practice is founded".

Having identified how routines and work practices are interrelated, and why they are important, we now move to discussing how work practices change due to IS innovation deployment and evaluation. 


\subsection{Virtualisation and invisibility}

It is argued that deploying IS innovations such as telehealth and electronic records make medicine a virtual practice and predispose these work practices to become invisible (Mort et al., 2003; Mort \& Smith, 2009; Sandelowski, 2001).

There are different forms of invisible work, and in this research disembedding background work is considered as one such form. Disembedding background work is the work where although the individual is visible to others, the extent and severity of their work practices is rather invisible (Star \& Strauss, 1999; Oudshoorn, 2008; Nicolini, 2006). One example of such work is that of nurses.

Disembedding background work due to IS innovation deployment and evaluation originates due to virtualisation of clinical encounter, particularly in case of telehealth. This virtualisation apart from having an impact on interaction between the patient and nurse, also influences trust as telehealth involves "faceless commitments" that are based on trustworthiness vested in technology. Nursing practice without telehealth however, involves trustworthiness established between different individuals based on "facework commitments", due to physical presence of those involved. In other words, introduction of disembedding work such as virtualisation of clinical encounter calls for investing trust "not in individuals but in abstract capacities" (Giddens, 1990; Kouroubali, 2002; Nicolini, 2007; Nicolini, 2010; Bhattacherjee \& Hikmet, 2007; Berg, 2003).

Disembedding work can also be perceived as threat to expertise. This stems from changes to skill set and predisposing one's experience due IS innovation deployment and evaluation. In addition, individual's resistance to disembedding work could also be enacted due to concerns pertaining to the impact of change on standards of care delivery (Nicolini, 2006, 2007; Wears \& Berg, 2005; Waterworth et al., 1999). This notion of change having an impact on the quality of care is well documented by Donabedian in his work, and it is discussed next.

\subsection{Structure, process and outcome framework}

According to this framework, the impact of IS innovation on quality of care can be evaluated through seven attributes (Donabedian, 2003):

- Efficacy

The ability of science and technology of healthcare to bring about improvements in health when used under the most favourable circumstances

- Effectiveness

The degree to which attainable improvements in health are, in fact, attained

- Efficiency

The ability to lower the cost of care without diminishing attainable improvements in health

- Optimality

The balancing of improvements in health against the costs of such improvements

- Acceptance

Conformity to the wishes, desires, and expectations of patients and their families

- Legitimacy

Conformity to social preferences as expressed in ethical principles, values, norms, mores, laws, and regulations 
- Equity

Conformity to a principle that determines what is just and fair in the distribution of health care and its benefits among members of the population

Many researchers have used this "triad" to explain the process of IS innovation deployment and evaluation such as electronic prescribing and administration system, in healthcare setting (Runciman, 2010; Cornford et al., 1994; Barber et al., 2007).

This concept allows to establish a link between deployment of healthcare innovations such as telehealth, and electronic records, and perception of healthcare professionals pertaining to impact on quality of care. It therefore, enables defining attributes of recursive relationship between healthcare social system and the human agent, and between the healthcare social system and IS innovation as presented in the next section.

\section{Triality framework}

By drawing on the all the theoretical concepts discussed in this chapter, the conceptual framework can now be presented in its entirety. Where according to the previous version, the Triality framework acknowledged that the technological innovation, healthcare social system, and human agent are interrelated to each other through recursive relationship, the new version identifies set of attributes attached to each of the recursive relationship. The framework further provides an understanding on how and why these attributes are articulated, and thus facilitates gaining a deeper insight into the deployment and evaluation processes.

In addition, the framework encompasses the notion that each attribute influences work routines which are described here as social practices that are enacted by interactions of individuals whose actions are interdependent with the actions of other individuals within the complex context of healthcare.

The Triality framework has many advantages. It ensures multilevel analysis that is longitudinal in nature; responds to the calls for furthering the use of theoretical perspectives in the field of healthcare (Davidson \& Chiasson, 2004; Cho, 2007; Greenhalgh et al., 2009); encompasses the 10-e's of e-health described by Eysenbach (2001), and the notion of complex healthcare intervention described by authors such as May and colleagues (2007a, 2007b), and Campbell et al., (2000) within IS innovation.

\subsection{Attributes of relationship between IS innovation and healthcare social system}

The three attributes at this level attributes are drawn from SCOT and Donabedian's work on quality of care, and illustrate how the design of IS innovation is influenced by, and influences the healthcare social system; and how the use of IS innovation is assessed on the basis of efficiency and effectiveness, and optimality and equity.

- Design

The balance of IS innovation design against the needs and requirements of the end-user, and its ability to fulfil and meet the outlined needs and requirements through its design (and design features), without being cost intensive.

Innovation design is one of biggest factors that determine whether it will be used by users and assimilated in their work practices (Orlikowski \& Icano, 2001; Greenhalgh et al., 2009). 


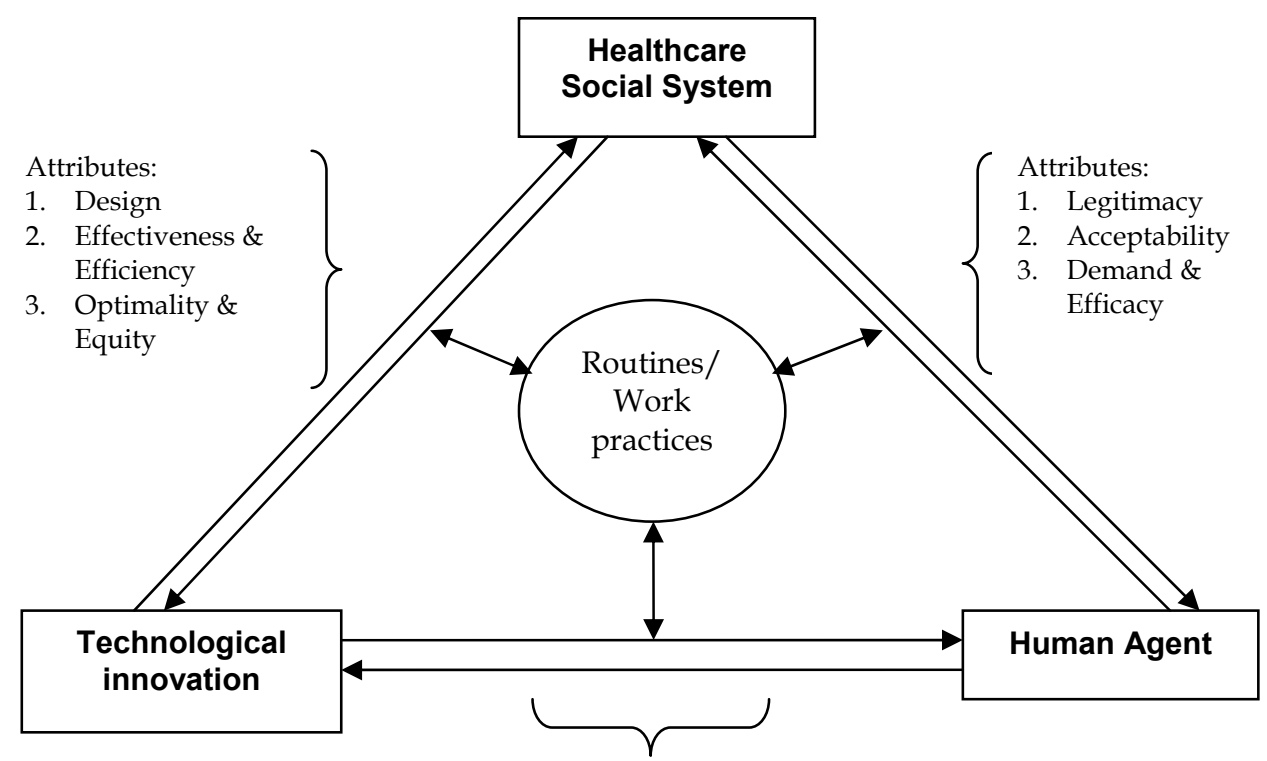

Attributes:

1. Expertise

2. Interaction

3. Trust

Fig. 2. The Triality framework (final version)

The tension between the design as needed and as provided is created due to many factors such as contextual issues, regulatory issues, financial margins etc; and in many cases it is the end user who decides how successful the design is, as according to Chau and Hu's (2001, 2002) study, healthcare professionals use a technology that they perceive to be designed appropriately and fit well with their work practices.

- Efficiency

The ability of IS innovation to lower the time and allow someone to complete/carry out various different tasks thereby increasing productivity "and using time efficiently" at individual level

The ability of IS innovation to lower the cost without diminishing attainable improvements at system level, $\mathcal{E}$

- Effectiveness

The degree to which attainable improvements are attained at system level and individual level (adopted from Donabedian, 2003)

It is argued that healthcare professionals assess the efficiency and effectiveness by evaluating how the IS innovation might help them to deliver care and what impact it has on the patients. Often, efficiency is measured in terms of time saved during a routine task and how well it was performed. 
Effectiveness on the other hand is measured in terms of quality of improvement in care delivery processes and the outcome (pertaining to patient health) (Bannister \& Remenyi, 2003; Mair et al., 2007a, 2007b). Effectiveness in the field of healthcare is measured by applying various evaluating methodologies to an intervention and RCT is one such method (MRC 2000). Applicability of RCT to evaluate technological intervention has been questioned due many reasons. These include gaining ethical approval, defining selection criteria and recruiting patients, training staff and gaining their support (Rosen \& Mays, 1998).

- Optimality

The balancing of improvements in health against the cost of such an intervention (adopted from Donabedian, 2003), E

- Equity

The just and fair distribution of health care delivery among the patient population (adopted from Donabedian, 2003).

This attribute outlines that the healthcare professionals often question service procurement decisions due to doubts over cost spend and, benefit promised and realised (McDonald et al., 2006; Mair et al., 2007a, 2007b).

In addition, it is argued that healthcare professionals favour equitable distribution of IS innovation despite the innovation being at evaluation stage as some strategies such as RCT are not promoted well enough and in doing so the managers and teams involved in evaluation fail to adequately address the need for RCT and healthcare professionals role in it (Greenhalgh \& Russell, 2010; Mair et al., 2007a, 2007b; Berghout \& Remenyi, 2005).

\subsection{Attributes of relationship between healthcare social system and the human agent}

The three attributes at this level are deduced from ST and Donabedian's work on quality of care, and they highlight the structures enacted by the human agents as users of IS innovation within the healthcare system, where, by drawing on rules and resources the agents assess the compatibility and the need of such an innovation.

- Legitimacy

Compatibility of IS innovation and its conformity to the ethical issues, laws, regulations and values.

Healthcare professionals are known to make decisions that are bound by ethical and legal issues.

In particular, ethical issues arise due to evaluation strategies such as RCT as it governs the provision and allocation of equipment to patients (Finch et al., 2003, 2006; Heaven et al., 2006; Lankshear \& Mason, 2001; Greenhalgh \& Russell, 2010; McDonald et al., 2006; Ammenwerth et al., 2003).

- Acceptability

The degree to which IS innovation is compatible with the current job role and work routines, and conforms to the expectations of its users.

It is argued that both, the processes of IS innovation deployment and evaluation impact the work practices of healthcare professionals. This can be caused due to increased workload and redefining work roles (McDonald et al., 2006). 
However, it is also suggested that such instances of increased workload and change in roles are negotiated over time and become part and parcel of routinised work practices (Greenhalgh, 2009; May et al., 2007a, 2007b).

- Demand

The degree to which IS innovation is needed to improve healthcare delivery at individual level; and reduce cost at system level, $\mathcal{E}$

- Efficacy

The ability of IS innovation to bring about improvements in health of the patients (adopted from Donabedian, 2003).

It is argued that the demand of IS innovation is mainly dominated by users experience and perception; and the sense of efficacy mainly originates from the scientific evidence provided to back up the IS innovation deployment and evaluation through strategies as RCT (McGrath et al., 2008; Clark \& Goodwin, 2010; Cornford et al., 1994; Hibbert et al., 2004; Finch et al., 2008).

\subsection{Attributes of relationship between the human agent and the IS innovation}

The attributes at this level are conceived from ST and theory of normalisation, and they facilitate understanding the various dynamics that contribute to the human agent's perception and the practice they enact in response IS innovation deployment and/or its evaluation, and the implications this has on the assimilation of IS innovation in work practices.

- $\quad$ Expertise

Skills and knowledge required to use IS innovation in order to deliver better care to the patients (and enhance clinical encounter

Addition of IS innovation could be regarded as an agent responsible for introducing "expertise asymmetry" and can cause hindrance towards its assimilation (Lehoux et al., 2002; Sicotte \& Lehoux, 2003; Greenhalgh 2009).

In healthcare, expertise can be understood to be of two types: social expertise required during social interaction with patient and colleagues, and technical expertise employed in using the IS innovation correctly.

Expertise is affected by training and support (Gagnon et al., 2003, 2006; Sallas et al., 2007). In addition, Chau and $\mathrm{Hu}(2001,2002)$ found in their study, that staff support was credited for physicians' acceptance of technology; and it can be challenged due to status quo, power dynamics and autonomy.

- Interaction

Establishing new interaction patterns and ways of communicating between various individuals at different levels

Deployment and evaluation processes pertaining to IS innovation impact the normal interaction patterns of healthcare professionals with their colleagues and patients.

Particularly, changes to interactions during clinical encounter are more evident as May (1992) argues that healthcare professionals such as nurses interact with their patients to 
develop 'knowing', where it refers to developing an understanding of patient not as biomedical subject but as an individual with social and personal background and needs. This requires capturing the holistic picture which entails subjective data such as how did the patient look, and the objective data such as blood pressure, weight etc. However, such 'knowing' is affected by introducing IS innovations in work practices and changing the clinical encounter.

- $\quad$ Trust

Questioning the degree to which IS innovation is perceived to be reliable and safe

According to Giddens, trust serves to "reduce or minimise the dangers to which particular type of activity are subject", where "danger is understood as a threat to desired outcomes" (Giddens, 1990). A recent study by Sharma et al., $(2010,2011)$ contributes to this topic by arguing that trust impacts clinical users' decision on using the IS innovation provided, and on a similar note, Gagnon et al., (2006) argues that it affects users' readiness towards IS innovation such as telehealth.

Trust can be envisaged as technology trust, interpersonal trust and organisational trust (Li et al., 2008; Lippert \& Davis, 2006; Lippert \& Swiercz, 2005). Lippert and Davis (2006) evaluate the impact of trust on technology internalisation which refers to "the effective and continued use of technology over time" (Lippert \& Davis, 2006; Lippert \& Swiercz, 2005), and propose that greater degree of interpersonal trust and technology trust among the members of an organisation would lead to effectiveness in technology adoption and eventually achieve internalisation (Lippert \& Davis, 2006).

\section{Conclusion}

Triality Framework presents an argument that a 'recursive' relationship representing mutual interaction exists not only between two entities, but between all three interacting entities of context, content and the user. This interaction is enacted through various dynamics termed the attributes. The framework further:

- provides an understanding on how assimilation and routinization of technological innovation and its evaluation strategies changes over time.

- Highlights how users' decisions on using and accepting IS innovation and its evaluation strategies is influenced by disturbance in their work practices. These disturbances are mediated through the nine attributes outlined in the framework.

- provides understanding how a healthcare professional makes sense of the change introduced. In the process contributes to the knowledge of change management.

- By application of the nine attributes and the dynamics of their articulation, informs all those involved in e-health deployment and evaluation how to improve their approach.

\subsection{Limitations and future work}

Triality framework as presented in this chapter does not ascertain the significance of attributes statistically as is the case in models such as Technology Acceptance Model (TAM). Future research could consider using a method that involves statistical analysis and enable evaluating the strength of relationships between the attributes and express them as dependencies. 
In addition, the user as human agents in Triality framework mainly encompasses healthcare professionals such as doctors, nurses and technicians. They are viewed as the primary users of innovation. The framework does not consider patient. Future research could consider how to include the patient, as the role that a patient play in modern healthcare system has evolved to that of an expert patient. Research could also consider whether the involvement of patient as one of the primary users influences outcome, and whether there are any differences in ways different group of users perceive the innovation, its deployment and evaluation processes.

Last but not least, it is vital to note that Triality framework has been mainly presented to understand the challenges that the healthcare sector faces when new technological innovations are deployed and evaluated. Future research could consider how Triality framework can be mapped across other areas and whether the challenges facing other sectors are equally challenging.

\section{References}

AMMENWERTH, E., GRÄBER, S., HERRMANN, G., BÜRKLE, T. \& KÖNIG, J. (2003). Evaluation of health information systems - Problems and challenges. International journal of medical informatics, 71, pp. 125-135.

AVGEROU, C. (2002). Information Systems and Global Diversity. 1 edn. USA: Oxford University Press Inc.

AVGEROU, C. (2001). The significance of context in information systems and organizational change [Online]. LSE Research Online.

AVGEROU, C. \& MADON, S. (2004). Framing IS studies: understanding the social context of IS innovation. In: C. AVGEROU, C. CIBORRA and F. LAND, eds, The Social Study of Information and Communication Technology Innovation, Actors, and Contexts. 1 edn. New York: Oxford University Press, pp. 162-182.

BANNISTER, F., \& REMENYI, D. (2003). The Societal Value of ICT: First Steps Towards an Evaluation Framework. Electronic Journal of Information Systems Evaluation, 6, pp. 197-206

BARBER, N., CORNFORD, T., \& KLECUN, E. (2007). Qualitative evaluation of an electronic prescribing and administration system. Quality \& safety in health care, 16, pp.271278.

BARLEY, S. R. (1986). Technology as an Occasion for Structuring: Evidence from Observations of CT Scanners and the Social Order of Radiology Departments. Administrative Science Quarterly, 31, pp. 78-108.

BARLEY, S.R. \& TOLBERT, P.S. (1997). Institutionalization and structuration: Studying the links between action and institution. Organization Studies, 18, pp. 93-117.

Barlow,J. Bayer,S. Castleton,B. \& Curry, R. (2005) Meeting government objectives for telecare in

BERG, M., (2003). The Search for Synergy: Interrelating Medical Work and Patient Care Information Systems. Methods of information in medicine, 42, pp. 337-344.

BERGHOUT, E. \& REMENYI, D. (2005). The Eleven Years of the European Conference on IT Evaluation: Retrospectives and Perspectives for Possible Future Research" The Electronic Journal of Information Systems Evaluation, 8, pp. 81-98 
BHATTACHERJEE, A. \& HIKMET, N. (2007). Physicians' resistance toward healthcare information technology: a theoretical model and empirical test. European Journal of Information Systems, 16, pp. 725-737.

BIJKER, W.E., (1995). Of bicycles, bakelites, and bulbs : toward a theory of sociotechnical change. 1 edn. Cambridge:MA: MIT Press.

BLACK, J. L., CARLILE, R. P., \& REPENNING, P. N. (2004). A Dynamic Theory of Expertise and Occupational Boundaries in New Technology Implementation: Building on Barley's Study of CT Scanning. Administrative Science Quarterly, 49, pp. 572-607

Boddy, D., King, G., Clark, S. J., Heaney, D., \& Mair, F. (2009). The influence of context and process when implementing e-health. BMC Medical Informatics and Decision Making, 9:9, doi:10.1186/1472-6947-9-9

CAMPBELL, M., FITZPATRICK, A., HAINES, A., KINMONTH, L. A., SANDEROCK, P., SPIEGELHALTER, D., \& TYRER, P. (2000). Framework for design and evaluation of complex interventions to improve health. British Medical Journal, 321, pp. 694-696

CHAU, P.Y.K. \& HU, P.J. (2001). Examining a model of information technology acceptance by individual professionals: An exploratory study. Journal of Management Information Systems, 18, pp. 191-229.

CHAU, P.Y.K. \& HU, P.J. (2002). Investigating healthcare professionals' decisions to accept telemedicine technology: An empirical test of competing theories. Information and Management, 39(4), pp. 297-311.

CHO, S. (2007). A contextualist approach to telehealth innovations. PhD thesis. The Robinson College of Business of Georgia State University.

CHIASSON, M.W. \& DAVIDSON, E. (2004). Pushing the contextual envelope: Developing and diffusing IS theory for health information systems research. Information and Organization, 14, pp. 155-188.

CIBORRA, C.U. \& LANZARA, G.F. (1994). Formative contexts and information technology: Understanding the dynamics of innovation in organizations. Accounting, Management and Information Technologies, 4, pp. 61-86.

CLARK, M. \& GOODWIN, N. (2010). Sustaining innovation in telehealth and telecare. UK: WSD Action Network.

CONSTANTINIDES, P. \& BARRETT, M. (2006a). Large-scale ICT innovation, power, and organizational change: The case of a regional health information network. Journal of Applied Behavioral Science, 42, pp. 76-90.

CONSTANTINIDES, P. \& BARRETT, M. (2006b). Negotiating ICT development and use: The case of a telemedicine system in the healthcare region of Crete. Information and Organization, 16, pp. 27-55.

CORNFORD, T., DOUKIDIS, G. \& FORSTER, D. (1994). Experience with a structure, process and outcome framework for evaluating an information system. Omega, 22, pp. 491504.

CORNFORD, T. \& KLECUN-DABROWSKA, E. (2003). Images of Health Technology in National and Local Strategies. Methods of information in medicine, 42, pp. 353-359.

CRUICHSHANK, J. (2010). Healthcare without walls: a framework for delivering healthcare at scale. London. 2020health.

DAVIDSON, E. (2006). A technological frames perspective on information technology and organizational change. Journal of Applied Behavioral Science, 42, pp. 23-39. 
DAVIDSON, E. (2002). Technology frames and framing: A socio-cognitive investigation of requirements determination. MIS Quarterly: Management Information Systems, 26, pp. 329-358.

DAVIDSON, E. (1997). Changing frames or framing change? Social cognitive implications of organizational change during IT adoption. Hawaii International Conference on System Sciences (HICSS) Volume 3: Information System Track-Organizational Systems and Technology, pp. 475-484.

DESANCTIS, G. \& POOLE, M. (1994). Capturing the complexity in advanced technology use: Adaptative structuration theory. Organization Science, 5, pp. 121-146.

DONABEDIAN, A. (2003). An Introduction to Quality Assurance in Health Care. 1 edn. Oxford: Oxford University

DOPSON, S., FITZGERALD, L., \& FERLIE, E. (2008). Understanding Change and Innovation in Healthcare Settings: Reconceptualizing the Active Role of Context. Journal of change management, 8, pp. 213-231

Edmondson, c. a., Bohmer, M, R., \& Pisano, P, G. (2001). Disrupted Routines: Team Learning and New Technology Implementation in Hospitals Administrative Science Quarterly, 46 , pp. 685-716

EYSENBACH, G. (2001). What is e-health? Journal of Medical Internet Research, 3:e20.

FAULKNER, A. (2009). Medical technology into healthcare and society: a sociology of devices, innovation and governance. 1 edn. UK: Palgrave Macmillan.

FELDMAN, M.S. (2003). A performative perspective on stability and change in organizational routines. Industrial and Corporate Change, 12, pp. 727-752.

FELDMAN, M.S. (2000). Organizational Routines as a Source of Continuous Change. Organization Science, 11, pp. 611-629.

FELDMAN, M.S. \& PENTLAND, B.T. (2003). Reconceptualizing organizational routines as a source of flexibility and change. Administrative Science Quarterly, 48, pp. 94-118.

FELDMAN, M.S. \& RAFAELI, A. (2002). Organizational routines as sources of connections and understandings. Journal of Management Studies, 39, pp. 309-331.

FINCH, T., MAY, C., MORT, M. \& MAIR, F. (2006). Telemedicine, Telecare, and the Future Patient: Innovation, Risk and Governance. In: A. WEBSTER, ed, New Technologies in Healthcare Challenge, Change and Innovation. 1st edn. P McMillan, pp. 84-96.

FINCH, T.L., MAY, C.R., MAIR, F.S., MORT, M. \& GASK, L. (2003). Integrating service development with evaluation in telehealthcare: An ethnographic study. British medical journal, 327, pp. 1205-1208.

FINCH, T.L., MORT, M., MAIR, F.S. \& MAY, C.R. (2008). Future patients? Telehealthcare, roles and responsibilities. Health and Social Care in the Community, 16, pp. 86-95.

FITZGERALD, L., FERLIE, E., \& HAWKINS, C. (2003). Innovation in healthcare: how does credible evidence

GAGNON, M.-., DUPLANTIE, J., FORTIN, J.-. \& LANDRY, R. (2006). Implementing telehealth to support medical practice in rural/remote regions: What are the conditions for success? Implementation Science, 1, doi:10.1186/1748-5908-1-18

GAGNON, M.-., GODIN, G., GAGNÉ, C., FORTIN, J., LAMOTHE, L., REINHARZ, D. \& CLOUTIER, A. (2003). An adaptation of the theory of interpersonal behaviour to the study of telemedicine adoption by physicians. International journal of medical informatics, 71, pp. 103-115. 
GAMMON, D., JOHANNESSEN, L.K., SØRENSEN, T., WYNN, R. \& WHITTEN, P. (2008). An overview and analysis of theories employed in telemedicine studies: A field in search of an identity. Methods of information in medicine, 47, pp. 260-269.

GIDDENS, A.. (1991). Modernity and self-identity : self and society in the late modern age. Cambridge: Polity.

GIDDENS, A. (1990). The consequences of modernity. UK: Polity Press in association with Blackwell.

GIDDENS, A.. (1984). The constitution of society : outline of the theory of structuration. Cambridge: Polity.

GIDDENS, A. (1979). Central problems in social theory: action, structure and contradiction in social analysis. London (etc.): Macmillan.

GREENHALGH, T. (2008). Role of routines in collaborative work in healthcare organisations. British Medical Journal, 337, pp. 1269-1271

GREENHALGH, T., POTTS, H.W.W., WONG, G., BARK, P. \& SWINGLEHURST, D. (2009). Tensions and paradoxes in electronic patient record research: A systematic literature review using the meta-narrative method. Milbank Quarterly, 87, pp. 729788 .

GREENHALGH, T., ROBERT, G., MACFARLANE, F., BATE, P., \& KYRIAKIDOU, O. (2004). Diffusion of Innovations in Service Organizations: Systematic Review and Recommendations. The Milbank Quarterly, 82, pp.581-629.

GREENHALGH, T. \& RUSSELL, J. (2010). Why do evaluations of eHealth programs fail? An alternative set of guiding principles. PLoS Medicine, 7, doi:10.1371/journal.pmed.1000360.

GREENHALGH, T. \& STONES, R.. (2010). Theorising big IT programmes in healthcare: Strong structuration theory meets actor-network theory. Social Science and Medicine, 70, pp. 1285-1294.

GREENHALGH, T., STRAMER, K., BRATAN, T., BYRNE, E., MOHAMMAD, Y. \& RUSSELL, J. (2008). Introduction of shared electronic records: Multi-site case study using diffusion of innovation theory. British Medical Journal, 337, pp. 1040-1044.

HARDCASTLE, M.R., USHER, K.J. \& HOLMES, C.A. (2005). An overview of structuration theory and its usefulness for nursing research. Nursing Philosophy, 6, pp. 223-234.

HARRISON, I.M., KOPPEL, R. \& BAR-LEV, S. (2007). Unintended Consequences of Information Technologies in Health Care-An Interactive Sociotechnical Analysis. Journal of the American Medical Informatics Association, 42, pp. 542-549.

HEAVEN, B., MURTAGH, M., RAPLEY, T., MAY, C., GRAHAM, R., KANER, E. \& THOMSON, R. (2006). Patients or research subjects? A qualitative study of participation in a randomised controlled trial of a complex intervention. Patient education and counseling, 62, pp. 260-270.

HIBBERT, D., MAIR, F.S., MAY, C.R., BOLAND, A., O'CONNOR, J., CAPEWELL, S. \& ANGUS, R.M.. (2004). Health professionals' responses to the introduction of a home telehealth service. Journal of telemedicine and telecare, 10, pp. 226-230.

JACKSON, H.M., POOLE, M.S. and KUHN, T. (2002). THE SOCIAL CONSTRUCTION OF TECHNOLOGY IN STUDIES OF THE WORKPLACE. The handbook of new media: social shaping and consequences of ICTs. Lievrouw, A. L.; Livingstone, M. S. edn. SAGE Publications Ltd., pp. 236-253. 
JONES, M., ORLIKOWSKI, W. \& MUNIR, K. (2004). Structuration theory and information systems: A critical reappraisal. In: J. MINGERS and L. WILLCOCKS, eds, Social theory and philosophy for information systems. 1 edn. UK: John Wiley \& Sons, Ltd., pp. 297-328.

JONES, M.R. \& KARSTEN, H. (2008). Giddens's Structuration Theory and Information Systems Research. MIS Quarterly, 32, pp. 127-157.

KLEIN, H.K. \& KLIENMAN, L.D. (2002). The Social Construction of Technology: Structural Considerations. Science, Technology, \& Human Values, 27, pp. 28-52.

KOUROUBALI, A. (2002). Structuration Theory and Conception-Reality Gaps: Addressing Cause and Effect of Implementation Outcomes in Health Care Information Systems. Proceedings of the 35th Hawaii International Conference on System Sciences.

LANKSHEAR, G. \& MASON, D. (2001). Technology and ethical dilemmas in a medical setting: Privacy, professional autonomy, life and death. Ethics and Information Technology, 3, pp. 225-235.

LATOUR, B. (1999). On recalling ANT. In: J. LAW and J. HASSARD, eds, Actor Network Theory and after. 1 edn. UK: Blackwell Publishing, pp. 15-25.

LEE, T. (2004). Nurses' adoption of technology: Application of Rogers' innovation-diffusion model. Applied Nursing Research, 17, pp. 231-238.

LEHOUX, P., SICOTTE, C., DENIS, J., BERG, M. \& LACROIX, A. (2002). The theory of use behind telemedicine: : how compatible with physicians' clinical routines? Social science $\mathcal{E}$ medicine, 54, pp. 889-904.

LI, X., HESS, J. T., \& VALACICH, S. J. (2008) Why do we trust new technology? A study of initial trust formation with organizational information systems. Journal of Strategic Information Systems 17, pp 39-71

LIPPERT, S.K. \& DAVIS, M. (2006). A conceptual model integrating trust into planned change activities to enhance technology adoption behaviour. Journal of Information Science, 32, pp. 434-448.

LIPPERT, S.K. \& SWIERCZ, M. P. (2005). Human resource information systems (HRIS) and technology trust. Journal of Information Science, 31, pp. 340-353.

MAIR, F., FINCH, T., MAY, C., HISCOCK, J., BEATON, S., GOLDSTEIN, P. \& MCQUILLAN, S. (2007a). Perceptions of risk as a barrier to the use of telemedicine. Journal of telemedicine and telecare, 13, pp. 38-39.

MAIR, F.S., MAY, C., FINCH, T., MURRAY, E., ANDERSON, G., SULLIVAN, F., O'DONNELL, C., WALLACE, P. \& EPSTEIN, O. (2007b). Understanding the implementation and integration of e-health services. Journal of telemedicine and telecare, 13, pp. 36-37.

MAY, C. (2006a). Mobilising modern facts: Health technology assessment and the politics of evidence. Sociology of Health and Illness, 28, pp. 513-532.

MAY, C. (2006b). A rational model for assessing and evaluating complex interventions in health care. BMC Health Services Research, 6.

MAY, C. (1993). Subjectivity and culpability in the constitution of nurse-patient relationships. International journal of nursing studies, 30, pp. 181-192.

MAY, C. \& FINCH, T. (2009). Implementing, embedding, and integrating practices: An outline of normalization process theory. Sociology, 43(3), pp. 535-554.

MAY, C., FINCH, T., MAIR, F., BALLINI, L., DOWRICK, C., ECCLES, M., GASK, L., MACFARLANE, A., MURRAY, E., RAPLEY, T., ROGERS, A., TREWEEK, S., 
WALLACE, P., ANDERSON, G., BURNS, J. and HEAVEN, B., 2007a. Understanding the implementation of complex interventions in health care: The normalization process model. BMC Health Services Research, 7.

MAY, C., FINCH, T., MAIR, F. \& MORT, M. (2005). Towards a wireless patient: Chronic illness, scarce care and technological innovation in the United Kingdom. Social science \& medicine, 61, pp. 1485-1494.

MAY, C. \& ELLIS, N.T. (2001). When protocols fail: technical evaluation, biomedical knowledge, and the social production of 'facts' about a telemedicine clinic. Social science \& medicine, 53, pp. 989-1002.

MAY, C., GASK, L., ATKINSON, T., ELLIS, N., MAIR, F. \& ESMAIL, A. (2001). Resisting and promoting new technologies in clinical practice: the case of telepsychiatry. Social science \& medicine, 52, pp. 1889-1901.

MAY, C., HARRISON, R., FINCH, T., MACFARLANE, A., MAIR, F., WALLACE, P. \& FOR THE TELEMEDICINE ADOPTION STUDY GROUP. (2003a). Understanding the normalization of telemedicine services through qualitative evaluation. Journal of the American Medical Informatics Association, 10, pp. 596-604.

MAY, C., HARRISON, R., MACFARLANE, A., WILLIAMS, T., MAIR, F. \& WALLACE, P. (2003b). Why do telemedicine systems fail to normalize as stable models of service delivery? Journal of Telemedivine and Telecare, 9, pp. S1:25-S1:26.

MAY, C.R., MAIR, F.S., DOWRICK, C.F. \& FINCH, T.L. (2007b). Process evaluation for complex interventions in primary care: Understanding trials using the normalization process model. BMC Family Practice, 8.

MCDONALD, A.M., KNIGHT, R.C., CAMPBELL, M.K., ENTWISTLE, V.A., GRANT, A.M., COOK, J.A., ELBOURNE, D.R., FRANCIS, D., GARCIA, J., ROBERTS, I. \& SNOWDON, C. (2006). What influences recruitment to randomised controlled trials? A review of trials funded by two UK funding agencies. Trials, 7:9 doi:10.1186/1745-6215-7-9.

MCGRATH, K., HENDY, J., KLECUN, E., WILLCOCKS, L. \& YOUNG, T. (2008). Evaluating "connecting for Health": Policy implications of a UK mega-programme.

MEDICAL RESEARCH COUNCIL. (2000). A framework for development and evaluation of RCTs for complex intervention to improve health. UK.

MORT, M., MAY, C.R. \& WILLIAMS, T. (2003). Remote doctors and absent patients: Acting at a distance in telemedicine? Science Technology and Human Values, 28, pp. 274-295.

MORT, M. \& SMITH, A. (2009). Beyond information: Intimate relations in sociotechnical practice. Sociology, 43, pp. 215-231.

NICOLINI, D. (2010). Medical innovation as a process of translation: A case from the field of telemedicine. British Journal of Management, 21, pp. 1011-1026.

NICOLINI, D. (2007). Stretching out and expanding work practices in time and space: The case of telemedicine. Human Relations, 60, pp. 889-920.

NICOLINI, D. (2006). The work to make telemedicine work: A social and articulative view. Social Science and Medicine, 62, pp. 2754-2767.

ORLIKOWSKI, W.J. \& SCOTT, V.S. (2008). "Sociomateriality: challenging the separation of technology, work and organisation". Working paper series. LSE

ORLIKOWSKI, W.J. (2007). Sociomaterial practices: Exploring technology at work. Organization Studies, 28, pp. 1435-1448. 
ORLIKOWSKI, W.J. (2002). Knowing in practice: Enacting a collective capability in distributed organizing. Organization Science, 13, pp. 249-273.

ORLIKOWSKI, W.J. (2000). Using Technology and Constituting Structures: A Practice Lens for Studying Technology in Organizations. Organization Science, 11, pp. 404-428.

ORLIKOWSKI, W.J. (1992). The Duality of Technology: Rethinking the Concept of Technology in Organizations. Organization Science, 3, pp. 398-427.

ORLIKOWSKI, W.J. \& BAROUDI, J.J. (1991). Studying Information Technology in Organizations: Research Approaches and Assumptions. Information Systems Research, 2, pp. 1-28.

ORLIKOWSKI, W.J. \& GASH, C.D. (1994). Technological Frames: Making Sense of Information Technology in Organizations. ACM Transactions on Information Systems, 12, pp. 174-207.

ORLIKOWSKI, W.J. \& IACONO, C.S. (2001). Research Commentary: Desperately Seeking the "IT" in IT Research - A Call to Theorizing the IT Artifact. Information Systems Research, 12, pp. 121-134.

ORLIKOWSKI, J.W., WALSHAM, G., JONES, R.M. \& DEGROSS, I.J. eds. (1996). Information technology and changes in organisational work. 1 edn. UK: Chapman \& Hall.

OUDSHOORN, N. (2008). Diagnosis at a distance: The invisible work of patients and healthcare professionals in cardiac telemonitoring technology. Sociology of Health and Illness, 30, pp. 272-288.

PEDDLE, K. (2007). Telehealth in Context: Socio-technical Barriers to Telehealth use in Labrador, Canada. Computer Supported Cooperative Work, 16, pp. 595-614.

PETTIGREW, A.M. (1997). What is processual analysis. Scandinavian Journal of Management, 13, pp 337-348.

PETTIGREW, A.M. (1987). CONTEXT AND ACTION IN THE TRANSFORMATION OF THE FIRM. Journal of Management Studies, 24, pp. 649-670.

PETTIGREW, A.M. (1985). Contextualist research: a natural way to link theory and practice. In: E.E.E.A. LAWLER, ed, Doing research that is useful for theory and practice. San Francisco: Jossey-Bass, pp. 222-259.

PETTIGREW, A.M., WOODMAN, R.W. \& CAMERON, K.S. (2001). Studying organizational change and development: Challenges for future research. Academy of Management Journal, 44, pp. 697-713.

PICKERING, A. (1993). The Mangle of Practice: Agency and Emergence in the Sociology of Science. The American Journal of Sociology, 99, pp. 559-589

PINCH, J.T. \& BIJKER E. W. (1984). The Social Construction of Facts and Artefacts: or How the ociology of Science and the Sociology of Technology might Benefit Each Other. Social Studies of Science, 14, pp. 399-441.

POZZEBON, M. \& PINSONNEAULT, A. (2005). Challenges in Conducting Empirical Work Using Structuration Theory: Learning from IT Research. Organization Studies, 26, pp. 1353-1376.

Robert, G., Greenhalgh, T., MacFarlane, F., \& Peacock, R. (2009). Organisational factors influencing technology adoption and assimilation in the NHS: a systematic literature review. Report for the National Institute for Health Research Service Delivery and Organisation Programme.UK. 
Robert, G., Greenhalgh, T., MacFarlane, F., \& Peacock, R. (2010). Adopting and assimilating new non-pharmaceutical technologies into healthcare: a systematic review. Journal of Health Services Research \& Policy, 15, 243-250

ROGERS, M.E. ( 2003). Diffusion of innovations. 5 edn. Free Press.

ROSEN, R., \& MAYS, N. (1998). The impact of the UK NHS purchaser-provider split on the rational introduction of new medical technologies. Health policy, 43, pp 103-123

RUNCIMAN, B. (2010). Health Informatics. UK: British Computer Society.

SALLAS, B., LANE, S., MATHEWS, R., WATKINS, T. \& WILEY-PATTON, S. (2007). An iterative assessment approach to improve technology adoption and implementation decisions by healthcare managers. Information Systems Management, 24, pp. 43-57.

SANDELOWSKI, M. (2001). Visible humans, vanishing bodies, and virtual nursing: Complications of life, presence, place, and identity. Advances in Nursing Science, 24, pp. 58-70.

SCHULTZE, U. \& BOLAND, R. J. (2000). Knowledge management technology and the reproduction of knowledge work practices. Journal of Strategic Information Systems, 9, pp. 193-212.

SHARMA, U., BARNETT, J. \& CLARKE, M. (2011). Clinical users' perspective on telemonitoring of patients with long term conditions: Understood through concepts of Giddens's structuration theory \& consequence of modernity, Information Systems Theory: Explaining and Predicting Our Digital Society, Vol2.

SICOTTE, C. \& LEHOUX, P. (2003). Teleconsultation: Rejected and Emerging Uses. Methods of information in medicine, 42, pp. 451-457.

STAR, S.L. \& STRAUSS, A. (1999). Layers of Silence, Arenas of Voice: The Ecology of Visible and Invisible Work. Computer Supported Cooperative Work: CSCW: An International Journal, 8, pp. 9-30.

Symons, J.V. (1991). A review of information systems evaluation: content, context and process. European Journal of Information Systems, 1, pp. 205-212.

THOMPSON, A. (2004). Confessions of an IS consultant or the limitations of structuration theory. Cambridge Research Papers in Management Studies, No. 1.

TJORA, A.H. \& SCAMBLER, G. (2009). Square pegs in round holes: Information systems, hospitals and the significance of contextual awareness. Social Science and Medicine, 68, pp. 519-525.

VAAST, E. \& WALSHAM, G. (2005). Representations and actions: The transformation of work practices with IT use. Information and Organization, 15, pp. 65-89.

WALSHAM, G. (1997). IT and Changing Professional Identity: Micro-Studies and MacroTheory. Journal of the American Society for Information Sceince, 49, pp. 1081-1089.

WALSHAM, G. (1993). Interpreting information systems in organisations. 1 edn. US: John Wiley \& Sons Inc.

WALSHAM, G. \& HAN, K. (1991). Structuration Theory and Information Systems Research. Journal of Applied System Analysis, 17, pp. 77-85.

WALSHAM, G. \& WAEMA, T. (1994). Information systems strategy and implementation: a case study of a building society. ACM Transactions on Information Systems, 12, pp. 150-173.

WATERWORTH, S., MAY, C. \& LUKER, K. (1999). Clinical 'effectiveness' and 'interrupted' work. Clinical Effectiveness in Nursing, 3, pp. 163-169. 
WEARS, R.L. \& BERG, M.. (2005). Computer technology and clinical work: Still waiting for godot. Journal of the American Medical Association, 293, pp. 1261-1263.

WHITTEN, P. \& ADAMS, I. (2003). Success and failure: A case study of two rural telemedicine projects. Journal of telemedicine and telecare, 9, pp. 125-129.

WHITTEN, P., JOHANNESSEN, L.K., SOERENSEN, T., GAMMON, D. \& MACKERT, M. (2007). A systematic review of research methodology in telemedicine studies. Journal of telemedicine and telecare, 13, pp. 230-235.

WHITTEN, P. and MICKUS, M., 2007. Home telecare for COPD/CHF patients: Outcomes and perceptions. Journal of telemedicine and telecare, 13, pp. 69-73.

WHITTEN, P.S. \& MACKERT, M.S. (2005). Addressing telehealth's foremost barrier: Provider as initial gatekeeper. International Journal of Technology Assessment in Health Care, 21, pp. 517-521.

WILLIAMS, R. \& EDGE, D. (1996). The social shaping of technology. Research Policy, 25, pp. 865-899.

WOOTTON, R., DIMMICK, L.S. \& KVEDAR, C.J. eds. (2006). Home telehealth: connecting care within the community. 1 edn. UK: Royal Society of Medicine Press Ltd.

ZUBOFF, S. (1988). In the Age of the Smart Machine: The Future of Work and Power. 1 edn. US. 


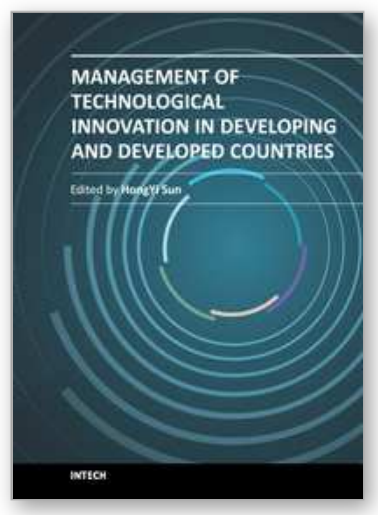

\section{Management of Technological Innovation in Developing and Developed Countries}

Edited by Dr. HongYi Sun

ISBN 978-953-51-0365-3

Hard cover, 312 pages

Publisher InTech

Published online 21, March, 2012

Published in print edition March, 2012

It is widely accepted that technology is one of the forces driving economic growth. Although more and more new technologies have emerged, various evidence shows that their performances were not as high as expected. In both academia and practice, there are still many questions about what technologies to adopt and how to manage these technologies. The 15 articles in this book aim to look into these questions. There are quite many features in this book. Firstly, the articles are from both developed countries and developing countries in Asia, Africa and South and Middle America. Secondly, the articles cover a wide range of industries including telecommunication, sanitation, healthcare, entertainment, education, manufacturing, and financial. Thirdly, the analytical approaches are multi-disciplinary, ranging from mathematical, economic, analytical, empirical and strategic. Finally, the articles study both public and private organizations, including the service industry, manufacturing industry, and governmental organizations. Given its wide coverage and multidisciplines, the book may be useful for both academic research and practical management.

\section{How to reference}

In order to correctly reference this scholarly work, feel free to copy and paste the following:

Urvashi Sharma, Julie Barnett and Malcolm Clarke (2012). Understanding Innovation Deployment and Evaluation in Healthcare: The Triality Framework, Management of Technological Innovation in Developing and Developed Countries, Dr. HongYi Sun (Ed.), ISBN: 978-953-51-0365-3, InTech, Available from: http://www.intechopen.com/books/management-of-technological-innovation-in-developing-and-developedcountries/understanding-innovation-deployment-and-evaluation-in-healthcare-the-triality-framework

\section{INTECH}

open science | open minds

\section{InTech Europe}

University Campus STeP Ri

Slavka Krautzeka 83/A

51000 Rijeka, Croatia

Phone: +385 (51) 770447

Fax: +385 (51) 686166

www.intechopen.com

\section{InTech China}

Unit 405, Office Block, Hotel Equatorial Shanghai

No.65, Yan An Road (West), Shanghai, 200040, China 中国上海市延安西路65号上海国际贵都大饭店办公楼405单元

Phone: +86-21-62489820

Fax: +86-21-62489821 
(C) 2012 The Author(s). Licensee IntechOpen. This is an open access article distributed under the terms of the Creative Commons Attribution 3.0 License, which permits unrestricted use, distribution, and reproduction in any medium, provided the original work is properly cited. 